Article

\title{
Impact of Heatwaves on the Physiology and Retail Meat Quality of Lambs
}

\author{
Minghao Zhang ${ }^{1}$, Robyn D. Warner ${ }^{1}{ }^{(}$, Frank R. Dunshea ${ }^{1,2}{ }^{(0}$, Kristy DiGiacomo ${ }^{1}{ }^{\circledR}$, Aleena Joy ${ }^{1}$, \\ Archana Abhijith ${ }^{1}$, Pragna Prathap ${ }^{1}$, Ting Ma ${ }^{1}$ and Surinder S. Chauhan ${ }^{1, *(1)}$
}

1 School of Agriculture and Food, The University of Melbourne, Melbourne 3010, Australia; minghao@student.unimelb.edu.au (M.Z.); robyn.warner@unimelb.edu.au (R.D.W.); fdunshea@unimelb.edu.au (F.R.D.); kristyd@unimelb.edu.au (K.D.); aleenajoyj@student.unimelb.edu.au (A.J.); apayyanakkal@student.unimeb.edu.au (A.A.); pprathap@student.unimelb.edu.au (P.P.); tingm1@student.unimelb.edu.au (T.M.)

2 Faculty of Biological Sciences, The University of Leeds, Leeds LS2 9JT, UK

* Correspondence: ss.chauhan@unimelb.edu.au

Citation: Zhang, M.; Warner, R.D.; Dunsheaa, F.R.; DiGiacomo, K.; Joy, A.; Abhijith, A.; Prathap, P.; Ma, T.; Chauhan, S.S. Impact of Heatwaves on the Physiology and Retail Meat Quality of Lambs. Foods 2022, 11, 414 https://doi.org/10.3390/

foods11030414

Academic Editor: Andrea Garmyn

Received: 24 December 2021

Accepted: 28 January 2022

Published: 31 January 2022

Publisher's Note: MDPI stays neutral with regard to jurisdictional claims in published maps and institutional affiliations.

Copyright: (C) 2022 by the authors. Licensee MDPI, Basel, Switzerland. This article is an open access article distributed under the terms and conditions of the Creative Commons Attribution (CC BY) license (https:// creativecommons.org/licenses/by/ $4.0 /)$.

\begin{abstract}
The experiment investigated the impact of heatwaves (HWs) on the physiology, postmortem muscle metabolism and meat quality of lambs. Seventy-two second-cross lambs (Poll Dorset $\times($ Border Leicester $\times$ Merino) ) were selected and exposed to either 1, 3 or 5 days of HWs or thermoneutal (TN) $\left(28-38{ }^{\circ} \mathrm{C}\right.$ and $40-60 \%$ relative humidity, $\left.\mathrm{RH} ; 18-21{ }^{\circ} \mathrm{C}, 40-55 \% \mathrm{RH}\right)$ conditions in climate-controlled chambers. Lambs exposed to 1-5 days of a HW exhibited higher respiration rates (RRs), rectal temperatures (RTs), skin temperatures (STs) and heart rates (HRs) compared to lambs exposed to an equal duration of TN conditions. However, HWs had no significant effects on muscle metabolism (rate and extent of $\mathrm{pH}$ decline, muscle glycogen and lactate content) and meat quality (cooking loss and shear force). Similarly, there were limited impacts of 1-5 days of HW on the colour $\left(L^{*}, a^{*}, b^{*}\right.$ and R630/580) and drip loss of the longissimus thoracis et lumborum (LTL) and semimembranosus (SM) muscles for 4 days' overwrap retail display. Results suggest that short-duration HWs (1-5 days) had significant negative effects on animal physiology but had no effect on the muscle metabolism and meat quality.
\end{abstract}

Keywords: heat stress; lamb meat; retail display; physiological performance

\section{Introduction}

Heat stress (HS) is one of the biggest challenges facing animal production over the summer months and is likely to be accentuated by climate change and global warming. High ambient temperature and humidity compromise animal production and welfare as animals cannot maintain core body temperature due to the extra heat load [1]. Research over the last decade has suggested that meat quality problems, such as dark-cutting (high ultimate $\mathrm{pH}$ ) or pale soft exudative (PSE, rapid $\mathrm{pH}$ fall post-mortem) meat, are more prevalent in summer [2-4]. However, direct impacts of HS on meat quality are not well understood and may vary depending upon the duration and severity of ambient temperature and animal species and breed [3]. A higher incidence of dark-cutting meat has been reported in small ruminants such as sheep and goats when the heat exposure period is longer than 1 month, resulting in lower feed intake and decreased body weight gain $[2,5,6]$. However, the effects of short-duration heat events, such as those experienced during a heatwave $(\mathrm{HW})$, on sheep meat quality remain unknown.

Previously, Lowe et al. [7] reported that $12 \mathrm{~h}$ HS $\left(33^{\circ} \mathrm{C}, 85-100 \% \mathrm{RH}\right)$ did not change the meat quality of Romney cross ewe lambs. Our study recently showed that 1 and 2 weeks of cyclic heat stress $\left(28-40{ }^{\circ} \mathrm{C}, 40-60 \% \mathrm{RH}\right)$ did not impact lamb meat quality [8,9]. However, recent climate data shows that 1-5 days are the most likely duration of summer HW in the majority of countries, including Australia [10], China [11] and the U.S. [12]. 
Furthermore, there are growing concerns that global warming will further aggravate the challenge of HS as the HWs are getting hotter, longer and more frequent [10]. Therefore, understanding the impacts of short-term heat events such as HWs on meat quality are required. This study was designed to investigate the potential effects of a simulated HW experiment on small ruminants' meat quality. The specific objective of this experiment was to assess the impact of three different HW durations ( 1 day, 3 days and 5 days) on the physiological and metabolic biomarkers, postmortem muscle metabolism and meat quality of lambs. We hypothesized that HWs will have negative impacts on the physiological parameters, which include RR, RT, HR and ST, and on the meat quality (glycolysis, colour, WHC and texture) of lambs, irrespective of the duration of the HW. The experiment result would further help estimate the economic losses associated with HWs and guide policy and decision making to develop appropriate strategies to reduce the negative impacts of HS and improve animal welfare and product quality.

\section{Materials and Methods}

This experiment and all treatment procedures for live animals were assessed and approved by the University of Melbourne Faculty of Veterinary and Animal Sciences Animal Ethics Committee (AEC ID 1914955.1).

\subsection{Animals and Experimental Design}

Seventy-two second-cross female lambs (Poll Dorset X (Merino X Border Leicester)) aged between 9-12 months and weighing $49.0 \pm 7.0 \mathrm{~kg}$ were procured from 3 different breeders in Northeast Victoria. The experiment was conducted using a randomized $2 \times 3$ factorial design with 6 consecutive replications. Lambs in each replication were randomly allocated to either HW or thermoneutral (TN) conditions for 1,3 , and 5 days (12 lambs for each group, 3 groups for HW and 3 groups for TN). Lambs were acclimatized to indoor group feeding ( 2 weeks) followed by 1 week of individual pen feeding before relocation into metabolism cages $(1.0 \times 0.5 \mathrm{~m}$ with polypropylene slat flooring that has a stable grip preventing sheep from slipping) and exposed to simulated HWs or TN conditions in the climatic chambers.

After 3 days of acclimatization in the climatic chambers, lambs were exposed to either TN $\left(18-21{ }^{\circ} \mathrm{C}, 45-55 \% \mathrm{RH}, n=12\right)$ or to a HW $\left(28{ }^{\circ} \mathrm{C}(16: 00\right.$ to $8: 00 \mathrm{~h})$ and $38{ }^{\circ} \mathrm{C}(8: 00$ to $16: 00 \mathrm{~h}), 40-60 \% \mathrm{RH}, n=12)$ for different thermal treatment times (1, 3 and 5 days) according to the experimental design. In the HW room, the heaters and humidifiers were turned on at 8:00 h to maintain the room temperature between 36 and $38{ }^{\circ} \mathrm{C}$ and $\mathrm{RH}$ between $40 \%$ and $60 \%$ until 16:00 h. After 16:00 h, the heater was turned off, and the air conditioning system set to maintain the room temperature between 26 and $28{ }^{\circ} \mathrm{C}$ overnight until the next day at 8:00 h. Room temperature and RH were recorded every $30 \mathrm{~min}$ by temperature-humidity data loggers (TechBrands, Electus Distribution, Rydalmere, Australia; mounted at $1 \mathrm{~m}$ height), and the temperature-humidity index (THI) was calculated using the following equation: $\mathrm{THI}=\mathrm{db}{ }^{\circ} \mathrm{C}-(0.31-0.31 \mathrm{RH}) \times\left(\mathrm{db}{ }^{\circ} \mathrm{C}-14.4\right)$ [13] and is presented in Figure 1 for the two treatments. Lambs were individually fed, and water was available throughout the day. The diet consisted of $25 \%$ oaten chaff and $25 \%$ lucerne chaff, combined with standard lamb finisher pellets which was formulated according to NRC, 2007 (50\% pellets: $14 \%$ protein, $8 \%$ crude fibre, $2 \%$ added salt, $1 \%$ added urea). Lambs were fed ad libitum with $2 \times$ maintenance requirements per day. The equation: feed intake $(\mathrm{kg} \mathrm{DM} /$ day $)=\mathrm{W}^{0.75} \times 450 / 1000 / \mathrm{ME}$ (maintenance energy) was used to calculate the animals' daily feed requirements throughout the experiment.

\subsection{Physiological Parameters}

Respiration rate (RR) was measured by counting the flank movements in $20 \mathrm{~s}$, and heart rate (HR) was measured with a stethoscope for $20 \mathrm{~s}$, then converted to RR or HR per minute. Skin temperature (ST) and Rectal temperature (RT) at the right flank were measured with a digital thermometer (EN60601, Welcare, SA, Australia). For skin temperature, the 
thermometer was placed in contact with the skin until the temperature reading stabilized. Both physiological parameters (HR, RR, RT and ST) were recorded at 8:00 h, 12:00 h and 16:00 $\mathrm{h}$ daily throughout the treatment period.

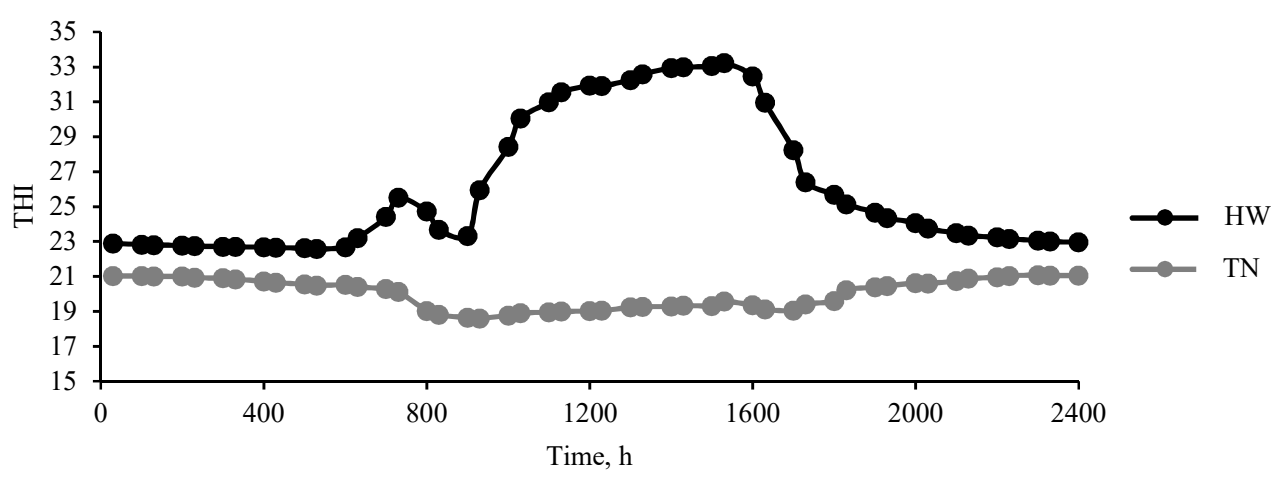

Figure 1. Average daily temperature humidity index (THI) recorded in the heatwave (HW) and the thermoneutral room (TN) during the experimental period. The average THI of the HW was 30.1 in the daytime and 23.9 in the nighttime (standard error difference of means $=0.55$ ) and the THI of the TN was 19.8 (standard error difference of means $=0.67$ ). THI $<22.2=$ no heat stress, 22.2 to 23.3 = moderate heat stress, 23.3 to $25.6=$ serve heat stress, $>25.6=$ extreme severe heat stress $[3,13]$.

\subsection{Slaughter}

At the end of each treatment period (day 1, 3 or 5 according to the treatment group), lambs were slaughtered using a licensed mobile abattoir after $12 \mathrm{~h}$ fasting, with access to water. The slaughter procedure was followed as standard commercial operations, including captive bolt stunning. The carcass was chilled in a mobile chiller at 0 to $4{ }^{\circ} \mathrm{C}$ for $24 \mathrm{~h}$ after slaughter, then the longissimus thoracis et lumborum (LTL) and semimembranosus (SM) muscles were removed from both sides of the carcass. Muscles were vacuum-packed, then stored at $0-4{ }^{\circ} \mathrm{C}$ in the mobile chiller until further measurements.

\section{Postmortem Muscle Sample Collection}

After slaughter and exsanguination, $30 \mathrm{~g}$-sample were collected from the Longissimus lumborum (LL) muscle at $5 \mathrm{~min}, 1 \mathrm{~h}, 2 \mathrm{~h}, 3 \mathrm{~h}, 4 \mathrm{~h}, 5 \mathrm{~h}, 12 \mathrm{~h}$ and $24 \mathrm{~h}$ postmortem. Muscle samples were snap-frozen in liquid nitrogen and stored in the freezer $\left(-80^{\circ} \mathrm{C}\right)$ for $\mathrm{pH}$ and metabolite analysis.

\subsection{Meat Quality}

\subsubsection{Meat Packaging and Retail Display}

At $48 \mathrm{~h}$ postmortem, LTL and SM muscles were cut into 5 pieces (140 g) and packaged for retail display. Samples were vacuum-packed for 4 days' aging and placed on a cello pad positioned in Cryovac black trays after aging $(170 \mathrm{~mm} \times 223 \mathrm{~mm}$, Sealed Air, Sydney, NSW, Australia). Trays were packaged with oxygen-permeable polyvinyl chloride film (Food cling wrap, Glad, Oakland, CA, USA). Meat samples were subsequently kept in a $4-6{ }^{\circ} \mathrm{C}$ in a refrigerator (display cabinet) with high-impact LED internal lighting on each side (maximum 18 W: GM1000LWCAS, Bromic, Sydney, NSW, Australia) for 4 days' retail display. Meat colour was measured every $24 \mathrm{~h}$ for 4 days' display, and water holding capacity (WHC) and Warner-Bratzler shear force (WBSF) were measured before and after 4 days' display.

\subsubsection{Surface Colour}

Meat colour (CIE-1986 mode [14], lightness $\left(L^{*}\right)$, redness/greenness $\left(a^{*}\right)$, and yellowness/blueness $\left(b^{*}\right)$ ) of muscle surface was measured in triplicate using a Hunter lab Miniscan $^{\mathrm{TM}}$ XE Plus 45/10 colorimeter (Reston, VA, USA). Measurements were made on day 0 , day 1 , day 2 , day 3 and day 4 on removal from the retail display case. The light source was set at illuminant D65 with the $10^{\circ}$ standard observer R-300 with $8 \mathrm{~mm}$ aperture, 
and the average of three readings were recorded [15]. Ratios between the reflectance at $630 \mathrm{~nm}$ and $580 \mathrm{~nm}$ (R630/580) were used to estimate the oxy/met ratio (also called redness in some papers) [16]. This ratio is a measure of meat colour stability over time.

\subsubsection{Water Holding Capacity}

Water holding capacity (WHC) was determined by measuring drip loss, cooking loss and purge loss of LTL and SM muscle samples at 0- and 4-days' display. Muscle drip loss was measured before retail display using the EZ-drip loss method and tubes purchased from Danish meat (DK) $[9,17]$. Muscle samples of $10 \mathrm{~g}$ and $17 \mathrm{~cm}$ thickness were collected by a circular knife. Then the sample weight was weighed as W1 and kept in the EZ-drip loss container at $4-6^{\circ} \mathrm{C}$. After $48 \mathrm{~h}$, samples were weighed again (W2), and the drip loss was calculated as: Drip loss $(\%)=\{(\mathrm{W} 1-\mathrm{W} 2) / \mathrm{W} 1\} \times 100$.

After colour measurements, meat samples were used for purge and cooking loss measurements. For purge loss, $90 \mathrm{~g}$ of muscle sample was weighed before (W1) and after (W2) 4 days' display. After purge loss weighing, the same muscle samples were cooked in plastic bags in a temperature-equilibrated water bath $\left(75^{\circ} \mathrm{C}\right.$; F38-ME, Julabo, Seelbach, Germany) until the core temperature reached $71^{\circ} \mathrm{C}$. The core temperature of muscle samples was monitored with a Grant thermometer equipped with T-type thermocouples (Grant Instruments, Cambridge, UK) during cooking. After cooking, muscles were cooled in iced water, stored at $0-4{ }^{\circ} \mathrm{C}$ in the mobile chiller for $12 \mathrm{~h}$, then weighed and recorded as W3 [18]. Purge and cooking loss calculation was calculated using the equation as follows: Purge loss $(\%)=\{(\mathrm{W} 1-\mathrm{W} 2) / \mathrm{W} 1\} \times 100 /$ Cooking loss $(\%)=\{(\mathrm{W} 2-\mathrm{W} 3) / \mathrm{W} 2\} \times 100$.

\subsubsection{Warner-Bratzler Shear Force}

After cooking-loss weighing, cooked samples were subjected to Warner-Bratzler peak shear force using the Lloud texture analyzer (TA-1, Lloyd Instruments, AMETEK, Berwyn, IL, USA), with the measurement protocol and setting adapted from previous established protocols by Minh Ha et al. [19]. Each sample was cut into 6 sub-samples $(1 \mathrm{~cm} \times 1 \mathrm{~cm} \times 4 \mathrm{~cm})$ with the direction of muscle fibers running longitudinally. The shear blade (V-shaped) was used for WBSF measurements with a $500 \mathrm{~N}$ load cell $(300 \mathrm{~mm} / \mathrm{min}$ shearing speed). Each sample was measured with 6 tests, and the average of 6 measurements was presented.

\subsection{Muscle $p H$, Glycogen and Lactates}

For determining the $\mathrm{pH}$ decline and glycolytic metabolite concentration in the muscle samples, muscle samples were collected at $5 \mathrm{~min}, 1 \mathrm{~h}, 2 \mathrm{~h}, 3 \mathrm{~h}, 4 \mathrm{~h}, 5 \mathrm{~h}, 12 \mathrm{~h}$ and $24 \mathrm{~h}$ postmortem, snap-frozen, then ground using a tissue grinder (20 s, 30 times/s). The $\mathrm{pH}$ of the muscle sample was measured using previously reported methods [20] with a slight modification [21]. Briefly, $100 \mathrm{mg}$ of powdered muscle sample was homogenized with $800 \mu \mathrm{L} 5 \mathrm{mM}$ iodoacetic acid and $150 \mathrm{mM} \mathrm{KCl}(\mathrm{pH}=7.0)$ buffer. After homogenization, the sample was centrifuged at $10,000 \times g$ for $5 \mathrm{~min}$. The $\mathrm{pH}$ was measured using a combined $\mathrm{pH}$ and temperature meter (WP-80M, TPS, Brendale, Australia) equipped with a spearhead $\mathrm{pH}$ probe (IJ44C probe, TPS, Brendale, Australia) and calibrated using 7.0 and $4.0 \mathrm{pH}$ buffers. For glycogen and lactate, $100 \mathrm{mg}$ muscle samples were homogenized with $1.0 \mathrm{~mL}$ distilled water, and then the sample was centrifuged at $13,000 \times g$ for 5 min (glycogen) or $10 \mathrm{~min}$ (lactate) to remove insoluble material [22]. The supernatant was used for glycogen and lactate concentration measurements using commercial assay kits (MAK016/MAK064, Sigma, San Jose, CA, USA).

\subsection{Statistical Analysis}

Statistical analysis adapted linear mixed model (REML) procedures in the GenStat 18th edition. For physiological parameters (RT, RR, HR, ST), fixed model effects were temperature (HW and TN), duration of temperature treatment (1, 3 or 5 days), and time of the day $(8: 00,12: 00,16: 00 \mathrm{~h})$. For the analysis of glycolysis parameters (muscle $\mathrm{pH}$, glycogen 
and lactate), fixed factors were temperature (HW and $\mathrm{TN})$, treatment $(1,3$ or 5 days) and postmortem time (only for $\mathrm{pH}$ decline). For meat quality parameters, temperature, treatment days and retail display times $(0,1,2,3$ and 4 days) were the fixed factors. Replication and sheep ID were used as random terms in the model for all analysis. Results are reported as means and standard errors of difference. Means were considered to differ significantly when $p \leq 0.05$, and group comparisons were conducted using LSD values.

\section{Results and Discussion}

\subsection{Temperature-Humidity Index and Physiological Parameters}

Temperature-humidity index (THI), which is calculated based on the ambient temperature and the relative humidity, is commonly used to measure heat stress. In this experiment, the average THI in the simulated HW room was 30.1 in the daytime and 23.9 at night, indicating that the lambs were exposed to high-temperature conditions during the day and were not able to offload heat overnight (Figure 1). As per the THI developed exclusively for sheep, a THI lower than 22.2 is classified as thermoneutral, a THI of 22.2 to 23.3 is moderate HS, a THI of 23.3 to 25.6 is classified as severe HS, and when THI exceeds 25.6 it is considered extremely severe HS [13,23].

Respiration rate, rectal and skin temperature, and heart rate responses to HW exposure are presented in Figure 2. Overall, there was a significant $(p<0.01)$ effect of HWs on all lamb physiological parameters (RR, RT, ST and HR) such that lambs exposed to 1, 3, and 5 days of a HW exhibited higher RR, RT, ST and HR than their counterparts in the TN group at 12:00 $\mathrm{h}$ and 16:00 $\mathrm{h}$. Lambs exposed to 5 days of a HW showed a significant increase in their resting respiration (recorded at 08:00 h) as compared to the lambs in TN group $(p<0.05)$, but this increase was not observed in the 1 and 3 days' group.

The increase in RR, RT and ST with exposure to a HW observed in this experiment agrees with previous research on HS in sheep [9,24-26]. The increase in RT is a commonly used indicator of HS observed when ambient temperature exceeds the species temperature threshold, and the animal can no longer maintain its core body temperature. The increase of RT in all HW (1, 3 and 5) groups as compared to TN sheep showed that a HW, irrespective of duration, perturbs the normal physiology of sheep and compromises their ability to regulate core body temperature. RR is increased by exposure to hot conditions in an effort to increase heat loss from the body as heat dissipation via water vapor in exhaled air is increased up to $60 \%$ in HS conditions compared to $20 \%$ in TN conditions [25]. RR and RT are considered standard physiological parameters to measure HS response in animals. Generally, sheep are considered to be suffering HS when RR reaches 200 breaths / min [27,28] and body temperature exceeds $39.9^{\circ} \mathrm{C}$ [29]. In this experiment, all $\mathrm{HW}$ groups ( 1 to 5 days) reached 200 breaths $/ \mathrm{min}$ at 12:00 $\mathrm{h}$ and 16:00 $\mathrm{h}$. As the heat load starts to accumulate in the animals with the increased duration of HW exposure, the basal RR also gradually increases as was observed in this study with the RR in the morning (08:00 h) increasing from 1 day to 5 days' HW exposure. The difference in RR between the 5-days HW and TN groups at 08:00 h $(p<0.05)$ showed that lambs accumulated more heat with heat exposure for 5 days as compared with 1 and 3 days' HW exposure, which typically happens with a HW because the lamb could not offload the heat-load during the warm night.

HWs also increased lambs' heart rates. The heart rate of the 1- and 3-day HW groups were significantly higher than the corresponding TN groups at 12:00 h and 16:00 h, and the 5-days HW group was higher than the TN group (5 days) at 16:00 h (Figure $2 ; p<0.05$ ). Heart rate is another important physiological parameter that is increased by exposure to high ambient temperature conditions to increase blood flow to the extremities to promote heat loss from the body. This increased blood flow helps sheep transfer heat from the interior of the body into the subcutaneous layer [30]. However, if the exposure to hot conditions is prolonged, HR may decrease due to peripheral vasodilation and lower metabolic rate under HS conditions [31]. 


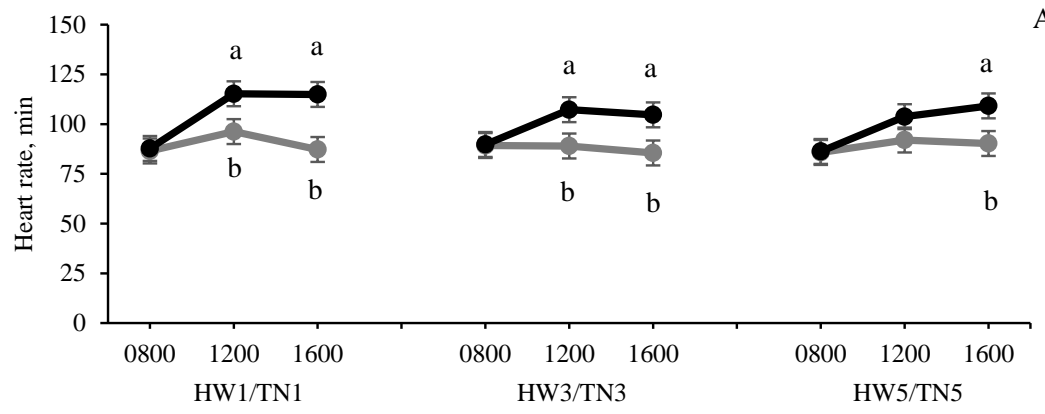

A
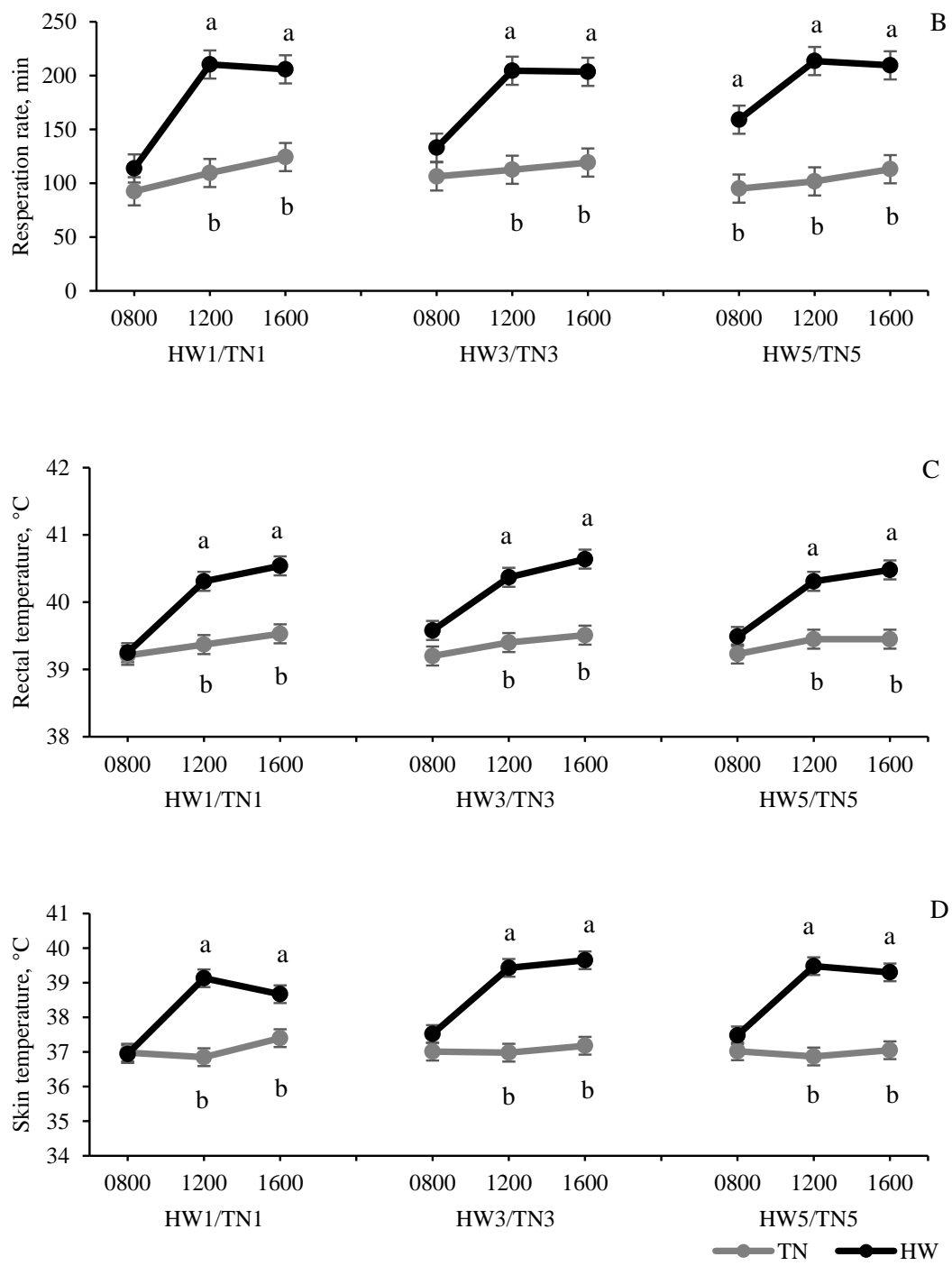

Figure 2. The effect temperature (thermoneutral, TN vs. heatwaves, HW) and heat exposure duration ( 1 vs. 3 vs. 5 days) have on physiological parameters of second-cross lambs at different times (8:00 h, 12:00 $\mathrm{h}, 16: 00 \mathrm{~h}$ ) on the last experiment day (Day 5); values are mean \pm SED; $a$ and $b$ indicate levels that are significantly different at $5 \%$ level of LSD in the same timepoint; HW/TN1-5 = 1 to 5 days HW/TN groups ( $n=12$ per group); heart rate, temp. $<0.001$; day $p=0.22$; temp. $\times$ day $p=0.43$ respiration rate, temp. $p<0.001$; day $p=0.54$; temp. $\times$ day $p=0.055$; rectal temperature, temp. $p<0.001$; day $p=0.65$; temp. $\times$ day $p=0.65$; skin temperature, temp. $p<0.001$; day $p=0.080$; temp. $\times$ day $p=0.062$. (A) Heart rate; (B) Respiration rate; (C) Rectal temperature; (D) Skin temperature. 


\subsection{Postmortem Muscle Glycolysis and Meat Quality}

After animals are slaughtered for meat, muscle glycogen is utilized under anaerobic conditions to achieve premortem homeostatic balance. This glycolytic metabolism results in the consumption of glycogen and the formation of lactate and $\mathrm{H}+$ ions, resulting in muscle $\mathrm{pH}$ decline from about 7.0 premortem to an ultimate $\mathrm{pH}$ of about 5.5. Any deviation from the normal rate and extent of postmortem muscle metabolism or glycolysis may lead to poor meat quality development, such as faster $\mathrm{pH}$ decline, resulting in PSE meat [28] or meat with a higher $\mathrm{pHu}$, called dark cutting in ruminants [30].

In this experiment, all HW treatments ( 1 to 5 days) had no impact on the initial $\mathrm{pH}$ of LTL muscle $(p>0.05)$ recorded $5 \mathrm{~min}$ postmortem (Figure 3). Regarding the $\mathrm{pH}$ decline over the $24 \mathrm{~h}$ postmortem period, only the 1-day HW group showed higher $\mathrm{pH}$ value (slower rate of $\mathrm{pH}$ decline) than the 1 -day TN group at $3 \mathrm{~h}$ and $4 \mathrm{~h}$ postmortem $(p<0.05)$. In contrast, the ultimate $\mathrm{pH}$ of both groups was the same $(p>0.05)$. There was no significant difference $(p>0.05)$ between different heat exposure times, and the interaction between temperature and time was not significant. Similar results were observed for postmortem muscle lactate and glycogen concentration, and there were no effects of HW on lactate and glycogen concentration in the LTL muscle samples collected at $24 \mathrm{~h}$ postmortem $(p>0.05)$.
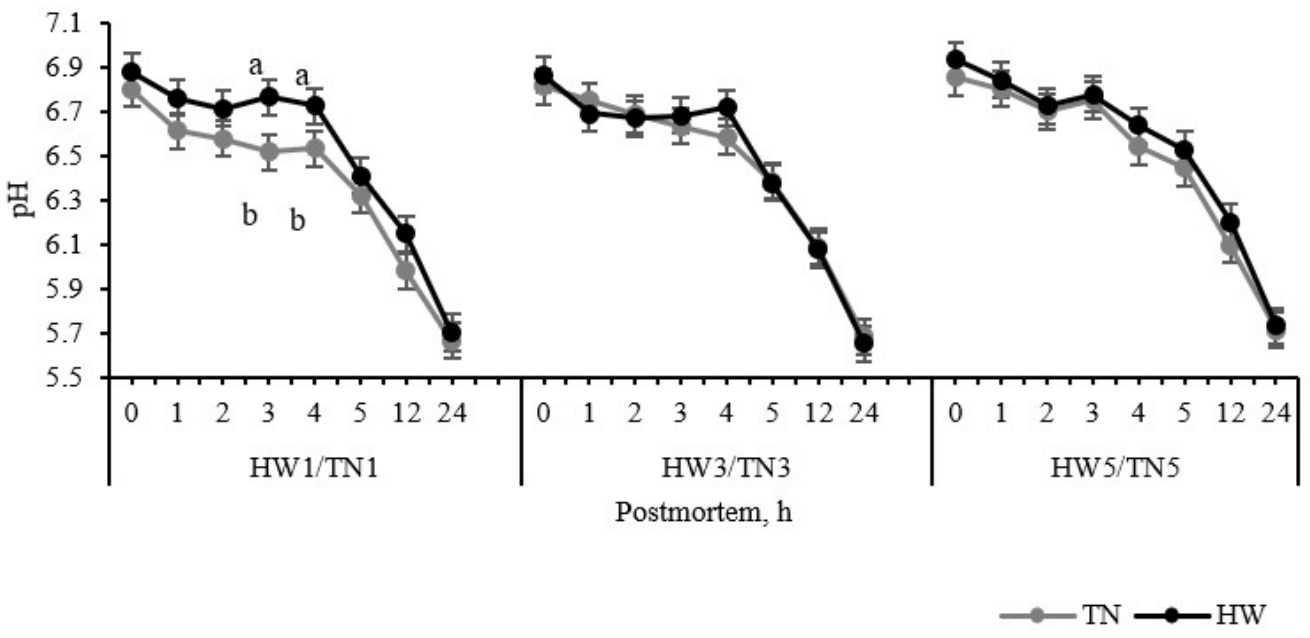

Figure 3. The effect of temperature (thermoneutral, TN vs. heatwaves, HW) and heat exposure duration ( 1 vs. 3 vs. 5 days) on $\mathrm{pH}$ drop of the longissimus thoracis et lumborum muscle at $5 \mathrm{~min}$, $1 \mathrm{~h}, 2 \mathrm{~h}, 3 \mathrm{~h}, 4 \mathrm{~h}, 5 \mathrm{~h}, 12 \mathrm{~h}, 24 \mathrm{~h}$ postmortem: values are mean \pm SED; a and b indicate levels that are significantly different at $5 \%$ level of LSD in the same timepoint; HW/TN1-5 = 1 to 5 days HW /TN groups ( $n=12$ per group); $\mathrm{pH}$ : temp. $p=0.12$; day $p=0.20$; temp. $\times$ day $p=0.31$.

Unlike the stress response observed in physiological parameters and similar to postmortem muscle glycolytic results, HWs had a very limited impact on retail meat colour performance and stability for both the LTL and SM muscles (Figures 4 and 5). HWs had a significant effect only on $a^{*}$ and $b^{*}$ values of LTL muscle $(p<0.05)$. The 3-day HW group had higher $\mathrm{a}^{*}$ and $b^{*}$ values than the 3 -day TN group. There was a significant correlation between temperature and retail display days for $a^{*}(p=0.054)$ of the SM such that the 1 day HW group showed faster discoloration (lower $a^{*}$ in 4 days' display) than the 3- and 5-day HW groups. There was no HW effect on R630/580 of the LTL and SM muscles. Similar to meat colour, HWs had limited influence on WHC and shear force (Tables 1 and 2) of both the LTL and the SM. All (1 to 5 days) HW groups had significant impact on drip loss of the LTL and drip loss and purge loss of the SM muscle $(p<0.05)$. For the LTL muscle, drip loss in 5 days in the TN group (1.95\%) was significantly higher than in the HW group (1.33\%), but the difference was not observed in the 3- and 1-day groups. Similar to the LTL muscle, the SM muscle drip loss and purge loss in the 1-day HW group was higher than in the 1-day TN group but 3- days groups had no difference. There was no difference in cooking loss between TN and HW groups before and after 4 days' retail display $(p>0.05)$. Similarly, HW 
had no influence on shear force of the LTL and SM muscle except in the 3-day HW group which showed higher values of the SM muscle before packaging ( $p<0.05 ; 0$ day) than the 3-day TN group. Compared with the LTL, the SM muscle showed a greater response in retail colour following exposure to a short-duration HW (1 day). Colour results of the SM muscle's $a^{*}$ from lambs exposed to a 1-day HW showed more changes compared with their TN counterparts, but this response was not seen in the LTL. This difference in response of the two muscles to acute stress (1-day HW) could be attributed to the higher percentage of type 1 muscle fibers and lower type 2B / X fibers in SM vs. LTL muscle [32-34]. Previous research has reported that muscle with a high percentage of type 1 and type $2 \mathrm{~A}$ (soleus) fibers had a more rapid and broader response to HS as signified by the rapid induction of heat shock protein, compared to Type $2 \mathrm{~B}$ or $2 \mathrm{X}$ muscle [35].

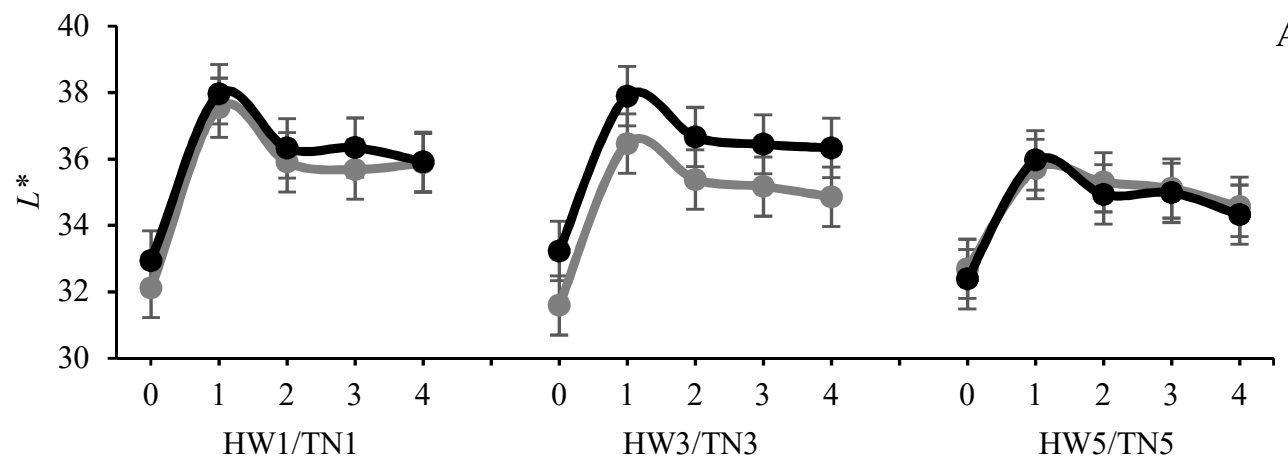

Retail display time, day

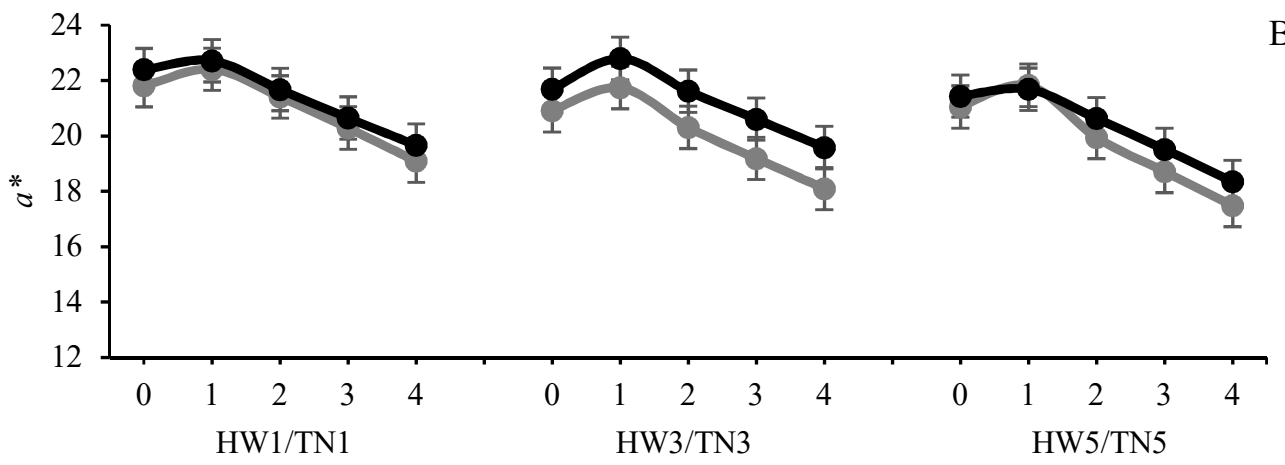

B

Retail display time, day

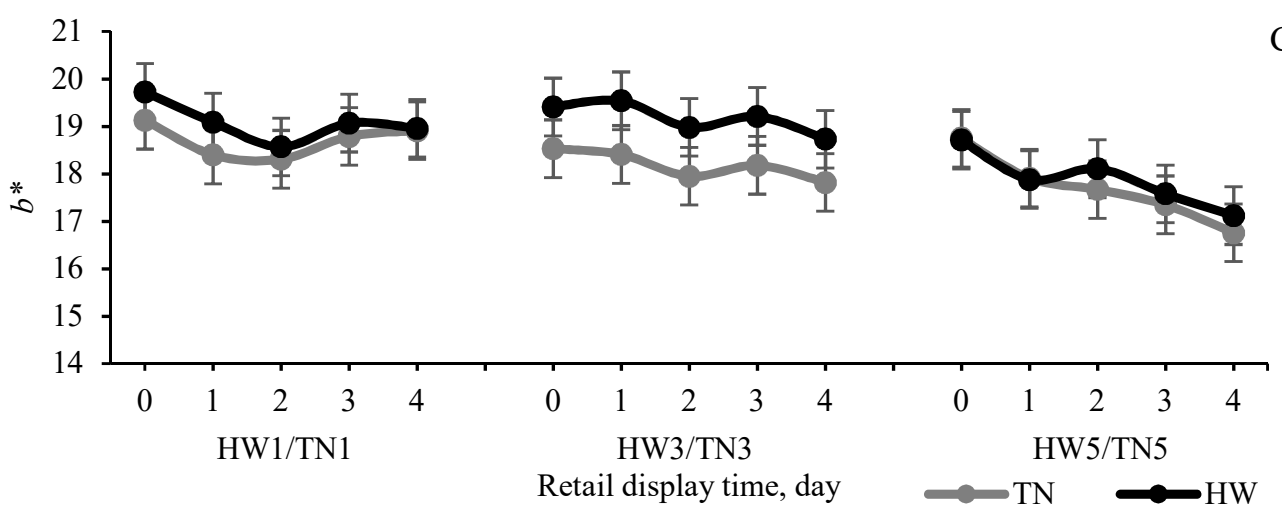

Figure 4. The effect of temperature (thermoneutral, TN vs. heatwaves, HW) and heat exposure duration ( 1 vs. 3 vs. 5 days) on lightness $\left(L^{*}\right)$, redness $\left(a^{*}\right)$, yellowness $\left(b^{*}\right)$ of longissimus thoracis et lumborum muscle in 4 days' overwrap retail display: values are mean \pm SED. HW $/ \mathrm{TN} 1-5=1$ to 5 days $\mathrm{HW} / \mathrm{TN}$ groups ( $n=12$ per group); lightness ( $L^{*}$; temp. $p=0.24$; day $p=0.19 ;$ temp. $\times$ day $p=0.43)$; redness $\left(a^{*}\right.$; temp. $p=0.046$; day $p=0.054$; temp. $\times$ day $\left.p=0.68\right)$; Yellowness $\left(b^{*}\right.$ : temp. $p=0.046$; day $p=0.001$; temp. $\times$ day $p=0.68)$. (A) lightness $\left(L^{*}\right) ;(\mathbf{B})$ redness $\left(a^{*}\right) ;(\mathbf{C})$ yellowness $\left(b^{*}\right)$. 


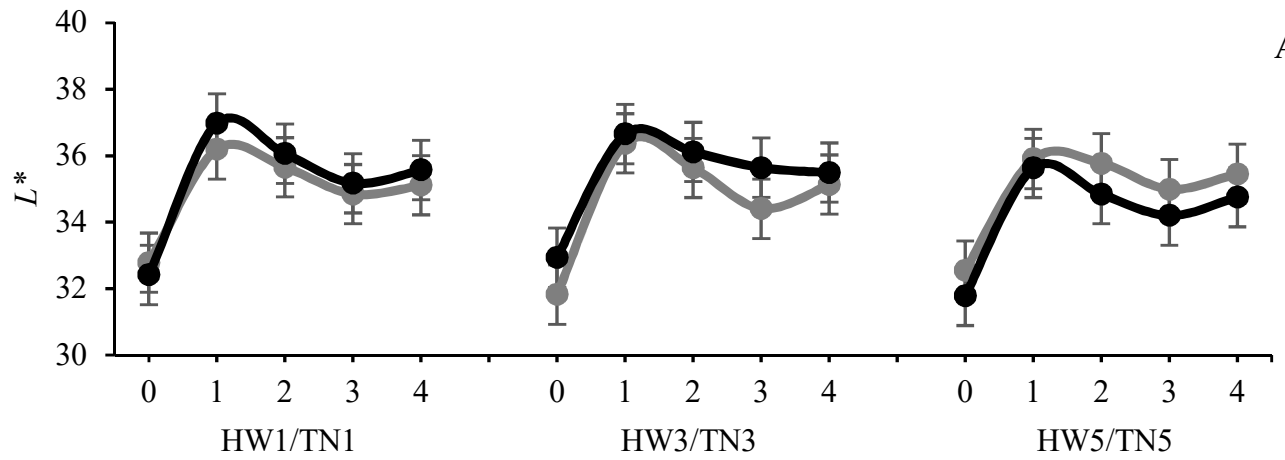

Retail display time, $\mathrm{d}$

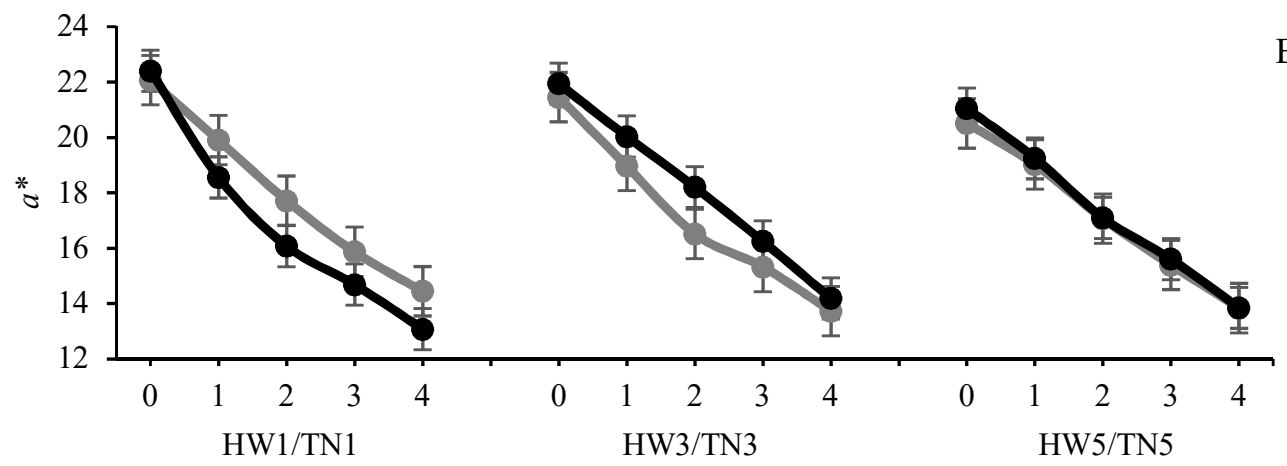

Retail display time, $\mathrm{d}$

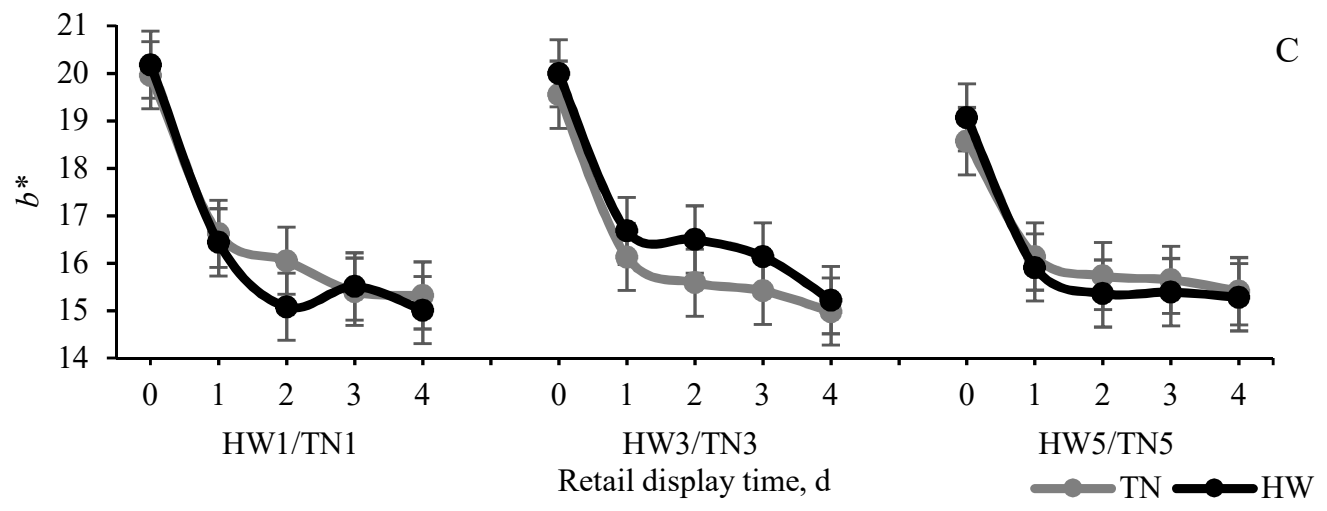

Figure 5. The effect temperature (thermoneutral, TN vs. heatwaves, $\mathrm{HW}$ ) and heat exposure duration ( 1 vs. 3 vs. 5 days) on lightness $\left(L^{*}\right)$, redness $\left(a^{*}\right)$, yellowness $\left(b^{*}\right)$ of semimembranosus muscle in 4 days' overwrap retail display: values are mean \pm SED; HW/TN1-5 $=1$ to 5 days HW /TN groups; temp. $=$ temperature $\left(\mathrm{n}=12\right.$ per group); lightness $\left(L^{*}\right.$; temp. $p=0.73$; day $p=0.64 ;$ temp. $\times$ day $p=0.42)$; redness $\left(a^{*}\right.$; temp. $p=0.95$; day $p=0.51$; temp. $\times$ day $\left.p=0.054\right)$; yellowness $\left(b^{*}\right.$ : temp. $p=0.62$; day $p=0.39$; temp. $\times$ day $p=0.35)$. (A) lightness $\left(L^{*}\right) ;(\mathbf{B})$ redness $\left(a^{*}\right) ;(\mathbf{C})$ yellowness $\left(b^{*}\right)$.

Across all the results from this experiment, it is evident that short duration heatwaves (1- to 5-day HW) applied in our experiment had no impact on postmortem muscle metabolites and $\mathrm{pH}$ decline and very limited impact on retail meat quality in lambs. There is no published data reporting the impact of short duration heat exposure of less than 1 week on the meat quality or metabolism of small ruminants. Previous research investigating the impact of HS on small ruminant meat quality has reported that HS leads to higher dark-cutting frequency and higher ultimate $\mathrm{pH}$ when the high ambient temperature exposure period is longer than 1 month [2,4]. For example, et al [5] reported that seasonal HS ( $35^{\circ} \mathrm{C}, 47 \%$ RH; 6 months) significantly decreased the $L^{*}, a^{*}$ and $b^{*}$ of psoas major and minor muscles of Omani Somali goats and Somali Merino sheep when compared with cool-season feeding $\left(21^{\circ} \mathrm{C}, 59 \% \mathrm{RH}\right)$. Gregory [2] also confirmed that the meat quality of animals is compromised more in summer than in other seasons. Macías Cruz [36] reported 
that 1 month of summer feeding $\left(28.4{ }^{\circ} \mathrm{C}, 55.2 \%\right)$ had no detrimental effects on meat colour of hair breed sheep compared with the winter $\left(19.2{ }^{\circ} \mathrm{C}, 41.7 \% \mathrm{RH}\right)$. This was in accordance with the results reported by Archana et al. [37] where 1 month of $\mathrm{HS}\left(28\right.$ and $40{ }^{\circ} \mathrm{C}$ and $29-58 \% \mathrm{RH}$ ) only increased the ultimate $\mathrm{pH}$ and decreased $L^{*}$ of the LTL muscle of Osmanabadi goats, but had no impact on $a^{*}, b^{*}$ and WHC. We have previously shown that the muscle $\mathrm{pH}$ and meat quality in lamb was not affected after 2 weeks or 1 week controlled HS exposure $\left(28-40{ }^{\circ} \mathrm{C}, 30-40 \% \mathrm{RH}\right)[9,38]$. Similar to the current study, we had observed that the lambs' physiological and blood gas parameters were significantly affected by HS but not the meat quality and muscle $\mathrm{pH}$ [26]. These results also agree with previous work of Lowe, et al. [7], who reported that $12 \mathrm{~h}$ of HS did not change sheep meat quality.

Table 1. The effect of temperature (thermoneutral, TN vs. heatwaves, HW) and heat exposure duration ( 1 vs. 3 vs. 5 days) on drip, purge and cooking loss of longissimus thoracis et lumborum (LTL) and semimembranosus (SM) muscle in 4 days' overwrap retail display in lambs ( $n=12$ per group).

\begin{tabular}{|c|c|c|c|c|c|c|c|c|c|c|}
\hline & \multicolumn{2}{|c|}{1 Day } & \multicolumn{2}{|c|}{3 Days } & \multicolumn{2}{|c|}{5 Days } & \multirow[t]{2}{*}{ SED $^{1}$} & \multicolumn{3}{|c|}{$p$-Value } \\
\hline & $\mathrm{TN}$ & HW & $\mathrm{TN}$ & HW & $\mathrm{TN}$ & HW & & Temp. ${ }^{2}$ & Day & $\mathbf{T} \times \mathbf{D}^{3}$ \\
\hline \multicolumn{11}{|l|}{ LTL } \\
\hline Drip loss & $2.02^{\mathrm{a}}$ & $1.65^{\mathrm{ab}}$ & $2.10^{\mathrm{a}}$ & $1.74^{\mathrm{ab}}$ & $1.95^{\mathrm{a}}$ & $1.33^{b}$ & 0.287 & 0.01 & 0.36 & 0.77 \\
\hline Purge loss /\% & 2.47 & 2.34 & 2.54 & 2.44 & 2.32 & 2.45 & 0.194 & 0.24 & 0.17 & 0.97 \\
\hline $\begin{array}{c}\text { Cooking loss } 0 \\
\text { day } / \%\end{array}$ & 19.9 & 19.8 & 20.6 & 20.9 & 20.5 & 18.9 & 1.22 & 0.50 & 0.41 & 0.50 \\
\hline $\begin{array}{c}\text { Cooking loss } 4 \\
\text { days } / \%\end{array}$ & 22.8 & 23.8 & 23.6 & 23.2 & 22.7 & 23.3 & 0.97 & 0.46 & 0.73 & 0.62 \\
\hline \multicolumn{11}{|l|}{ SM } \\
\hline Drip loss & $1.55^{\mathrm{a}}$ & $1.23^{\mathrm{b}}$ & $1.42^{\mathrm{a}}$ & $1.36^{\mathrm{ab}}$ & $1.22^{b}$ & $1.07^{\mathrm{b}}$ & 0.157 & 0.04 & 0.07 & 0.52 \\
\hline Purge loss $/ \%$ & $3.43^{\mathrm{a}}$ & $2.62^{b}$ & $2.96^{\mathrm{ab}}$ & $2.83^{\mathrm{ab}}$ & $2.76^{b}$ & $2.36^{b}$ & 0.332 & 0.02 & 0.13 & 0.36 \\
\hline $\begin{array}{c}\text { Cooking loss } 0 \\
\text { day } / \%\end{array}$ & $18.8^{\mathrm{ab}}$ & $18.9^{\mathrm{ab}}$ & $20.1^{\mathrm{a}}$ & $18.4^{\mathrm{ab}}$ & $17.9^{a b}$ & $16.5^{b}$ & 1.41 & 0.24 & 0.11 & 0.63 \\
\hline $\begin{array}{c}\text { Cooking loss } 4 \\
\text { days } / \%\end{array}$ & 22.8 & 21.9 & 21.9 & 22.2 & 21.1 & 22.3 & 1.13 & 0.73 & 0.73 & 0.42 \\
\hline
\end{tabular}

Values are mean \pm SED; letters $a$ and $b$ in the same row mean a significant difference at $5 \%$ level of LSD ${ }^{1} \mathrm{SED}=$ Standard error of the difference of means; ${ }^{2}$ Temp. $=$ Temperature; ${ }^{3} \mathrm{~T} \times \mathrm{D}=$ Temperature $\times$ day.

Table 2. The effect temperature (thermoneutral, TN vs. heatwaves, HW) and heat exposure duration (1 vs. 3 vs. 5 days) on Warner-Bratzler shear force (WBSF) of longissimus thoracis et lumborum (LTL) and semimembranosus (SM) muscles during 4 days' overwrap retail display ( $n=12$ per group).

\begin{tabular}{|c|c|c|c|c|c|c|c|c|c|c|}
\hline & \multicolumn{2}{|c|}{1 Day } & \multicolumn{2}{|c|}{3 Day } & \multicolumn{2}{|c|}{5 Day } & \multirow[t]{2}{*}{ SED $^{1}$} & \multicolumn{3}{|l|}{$p$-Value } \\
\hline & TN & HW & TN & HW & TN & HW & & Temp. ${ }^{2}$ & Day & $\mathbf{T} \times \mathrm{D}^{3}$ \\
\hline \multicolumn{11}{|l|}{ LTL } \\
\hline WBSF 0 day & 27.9 & 31.3 & 35.0 & 32.1 & 30.6 & 27.2 & 36.6 & 0.13 & 0.16 & 0.99 \\
\hline WBSF 4 days & 23.9 & 25.9 & 30.0 & 28.6 & 29.9 & 26.4 & 35.3 & 0.64 & 0.21 & 0.55 \\
\hline \multicolumn{11}{|l|}{ SM } \\
\hline WBSF 0 day & $40.9^{a}$ & $36.9^{a b}$ & $33.1^{\mathrm{b}}$ & $39.6^{a}$ & $33.5^{b}$ & $36.9^{a b}$ & 29.1 & 0.32 & 0.19 & 0.04 \\
\hline WBSF 4 days & 26.6 & 26.0 & 23.6 & 25.3 & 24.8 & 26.2 & 20.0 & 0.45 & 0.43 & 0.70 \\
\hline
\end{tabular}

Values are mean \pm SED; letters $a$ and $b$ in the same row mean a significant difference at $5 \%$ level of LSD; ${ }^{1} \mathrm{SED}=$ Standard error of the difference of means ${ }^{2}$ Temp. $=$ Temperature; ${ }^{3} \mathrm{~T} \times \mathrm{D}=$ Temperature $\times$ day.

Overall, results from this study are in accordance with the previous study in goats which reported that despite the noticeable influence of transport on blood parameters indicating stress in live animals, this status did not decisively alter meat quality parameters $[39,40]$. While few studies suggest that transportation under hot conditions $\left(42^{\circ} \mathrm{C} ; 6 \mathrm{~h}\right)$ may negatively impact ruminant meat quality and $\mathrm{pH}[41,42]$, the impact of physiological perturbations caused by exposure to short durations of HS may not always manifest in the 
characteristics of the meat. Nevertheless, data from this study suggest that there is need to better manage lambs during a HW to reduce impact on their physiological functions, regardless of the impact on meat quality. In this experiment, lambs were able to cope with the HW by eliciting physiological heat loss mechanisms (increased respiration rate and heart rate, etc.) and were able to maintain muscle glycogen above the threshold levels for normal $\mathrm{pH}$ decline [21,43]. From the limited effect result of muscle $\mathrm{pH}(1$-day HW) and meat colour (1- and 3-day HW groups of LTL and SM), acute HS has limited effects on muscle $\mathrm{pH}$ (HW1) and meat colour (HW3 and HW1 of LTL and SM respectively) as was seen here as the lambs may not have enough opportunity to adapt to acute stress. It may take 2-3 days for lambs to adapt to an ambient temperature change, even if the lamb's physiological and blood parameters were changed [26]. The number of published studies focused on the relationship between short-term HS (less than 1 month) and meat quality is very limited and does not provide conclusive evidence. Furthermore, some of those studies include animals of different breeds with different heat resilience, and some studies have different exposure conditions of temperature and $\mathrm{RH}$ making it even more difficult to make comparisons (see review by Zhang, et al [3]). Therefore, a comprehensive study involving larger populations is required to demonstrate the impact of HS, of different durations and severity, on sheep meat quality.

\section{Conclusions}

Short duration HWs (1 to 5 days) did not affect the meat quality of lambs despite the significant perturbations in their normal physiology which is reflective of the animals' adaptive response to HS. These changes in the physiological parameters were elicited by sheep to cope with HS but were not severe enough to influence muscle glycogen levels at slaughter, $\mathrm{pH}$ decline and meat quality. Therefore, exposure of lambs to short duration HWs over summer may not directly impact their meat quality provided lambs are not exposed to any other stressor such as nutritional stress or transportation stress.

Author Contributions: Research conceptualization and experimental design, S.S.C., F.R.D., R.D.W., K.D., M.Z.; methodology, M.Z., S.S.C., F.R.D., R.D.W., K.D.; research execution, M.Z., A.J., A.A., S.S.C., P.P., T.M.; data analysis, M.Z., S.S.C., F.R.D.; manuscript writing and editing, M.Z., S.S.C., F.R.D., R.D.W., K.D.; funding acquisition, S.S.C. All authors have read and agreed to the published version of the manuscript.

Funding: This research was funded by The Faculty of Veterinary and Animal Sciences Start-up Fund provided to Dr Surinder S. Chauhan. Minghao Zhang received Graduate Research Scholarship and Lindsay and Alice Gamble trust fund scholarship provided by The Faculty of Veterinary and Animal Sciences, The University of Melbourne.

Institutional Review Board Statement: This experiment and all treatment procedures for live animals were assessed and approved by the University of Melbourne Faculty of Veterinary and Animal Sciences Animal Ethics Committee (AEC ID 1914955.1).

Informed Consent Statement: Not applicable.

Data Availability Statement: The datasets generated for this study are available on request to the corresponding author.

Acknowledgments: The authors acknowledge the facilities provided by The University of Melbourne and Faculty of Veterinary and Agricultural Sciences to conduct this research at the Animal Facility, University of Melbourne Dookie Campus, Victoria 3647, Australia.

Conflicts of Interest: The authors declare no conflict of interest. 


\section{References}

1. Aggarwal, A.; Upadhyay, R. Heat Stress and Reproduction; Springer India: New Delhi, India, 2013; pp. 79-111.

2. Gregory, N.G. How climatic changes could affect meat quality. Food Res. Int. 2010, 43, 1866-1873. [CrossRef]

3. Zhang, M.; Dunshea, F.R.; Warner, R.D.; DiGiacomo, K.; Osei-Amponsah, R.; Chauhan, S.S. Impacts of heat stress on meat quality and strategies for amelioration: A review. Int. J. Biometeorol. 2020, 64, 1613-1628. [CrossRef] [PubMed]

4. Gonzalez-Rivas, P.A.; Chauhan, S.S.; Ha, M.; Fegan, N.; Dunshea, F.R.; Warner, R.D. Effects of heat stress on animal physiology, metabolism, and meat quality: A review. Meat Sci. 2020, 162, 108025. [CrossRef] [PubMed]

5. Kadim, I.T.; Mahgoub, O.; Al-Marzooqi, W.; Al-Ajmi, D.S.; Al-Maqbali, R.S.; Al-Lawati, S.M. The influence of seasonal temperatures on meat quality characteristics of hot-boned, m. psoas major and minor, from goats and sheep. Meat Sci. 2008, 80, 210-215. [CrossRef]

6. Kadim, I.T.; Mahgoub, O.; Al-Ajmi, D.S.; Al-Maqbaly, R.S.; Al-Mugheiry, S.M.; Bartolome, D.Y. The influence of season on quality characteristics of hot-boned beef $\mathrm{m}$. longissimus thoracis. Meat Sci. 2004, 66, 831-836. [CrossRef]

7. Lowe, T.E.; Gregory, N.G.; Fisher, A.D.; Payne, S.R. The effects of temperature elevation and water deprivation on lamb physiology, welfare, and meat quality. Aust. J. Agric. Res. 2002, 53, 707-714. [CrossRef]

8. Chauhan, S.S.; Dunshea, F.R.; Plozza, T.E.; Hopkins, D.L.; Ponnampalam, E.N. The impact of antioxidant supplementation and heat stress on carcass characteristics, muscle nutritional profile and functionality of lamb meat. Animals 2020, 10, 1286. [CrossRef]

9. Zhang, M.; Warner, R.D.; Dunshea, F.R.; DiGiacomo, K.; Joy, A.; Abhijith, A.; Osei-Amponsah, R.; Hopkins, D.L.; Ha, M.; Chauhan, S.S. Impact of heat stress on the growth performance and retail meat quality of 2nd cross (Poll Dorset $\times($ Border Leicester $\times$ Merino)) and Dorper lambs. Meat Sci. 2021, 181, 108581. [CrossRef]

10. Cowan, T.; Purich, A.; Perkins, S.; Pezza, A.; Boschat, G.; Sadler, K. More Frequent, Longer, and Hotter Heat Waves for Australia in the Twenty-First Century. J. Clim. 2014, 27, 5851-5871. [CrossRef]

11. Li, Y.; Ding, Y.H.; Li, W.J. Observed trends in various aspects of compound heat waves across china from 1961 to 2015. J. Meteorol. Res. 2017, 31, 455-467. [CrossRef]

12. Rastogi, D.; Lehner, F.; Ashfaq, M. Revisiting recent U.S. Heat waves in a warmer and more humid climate. Geophys. Res. Lett. 2020, 47, e2019GL086736.

13. Marai, I.F.M.; El Darawany, A.A.; Fadiel, A.; Abdel-Hafez, M.A.M. Physiological traits as affected by heat stress in sheep-A review. Small Rumin. Res. 2007, 71,1-12. [CrossRef]

14. Colorimetry, Central Bureau of the CIE; The International Commission on Illumination: Vienna, Austria, 1986 ; pp. 64-65.

15. Abhijith, A. Effect of slaughter age and post-mortem days on meat quality of longissimus and semimembranosus muscles of Boer goats. Meat Sci. 2021, 175, 108466. [CrossRef] [PubMed]

16. Warner, R.D. Genotype and age at slaughter influence the retail shelf-life of the loin and knuckle from sheep carcasses. Aust. J. Exp. Agric. 2007, 47, 1190. [CrossRef]

17. Otto, G.; Roehe, R.; Looft, H.; Thoelking, L.; Kalm, E. Comparison of different methods for determination of drip loss and their relationships to meat quality and carcass characteristics in pigs. Meat Sci. 2004, 68, 401-409. [CrossRef]

18. Hopkins, D.L.; Ponnampalam, E.N.; van de Ven, R.J.; Warner, R.D. The effect of pH decline rate on the meat and eating quality of beef carcasses. Anim. Prod. Sci. 2014, 54, 407-413. [CrossRef]

19. Ha, M.; Dunshea, F.; Warner, R. Investigation of Tenderness and water Holding Capacity of aged Pork Loins in Two Packaging Systems; Final Report; Co-Operative Research Center for High Integrity Australian Pork, University of Melbourne: Parkville, VIC, Australia, 2017.

20. Bendall, J.R. Variability in rates of $\mathrm{pH}$ fall and lactate production in the muscles of cooling beef carcasses. Meat Sci. 1978, 2, 91-104. [CrossRef]

21. Chauhan, S.S.; LeMaster, M.N.; Clark, D.L.; Foster, M.K.; Miller, C.E.; England, E.M. Glycolysis and pH decline terminate prematurely in oxidative muscles despite the presence of excess glycogen. Meat Muscle Biol. 2019, 3. [CrossRef]

22. Margolis, L. Exercising with low muscle glycogen content increases fat oxidation and decreases endogenous, but not exogenous carbohydrate oxidation. Metabolism 2019, 97, 1-8. [CrossRef]

23. St Pierre, N.R. Economic losses from heat stress by US livestock industries. J. Dairy Sci. 2003, 86, E52. [CrossRef]

24. Srikandakumar, A.; Johnson, E.H.; Mahgoub, O. Effect of heat stress on respiratory rate, rectal temperature and blood chemistry in Omani and Australian Merino sheep. Small Rumin. Res. 2003, 49, 193-198. [CrossRef]

25. Wojtas, K.; Cwynar, P.; Kolacz, R. Effect of thermal stress on physiological and blood parameters in merino sheep. Bull. Vet. Inst. Pulawy 2014, 58, 283-288. [CrossRef]

26. Joy, A.; Dunshea, F.; Leury, B.; DiGiacomo, K.; Clarke, I.; Zhang, M.; Abhijith, A.; Osei Amponsah, R.; Chauhan, S.S. Comparative assessment of thermotolerance in dorper and second-cross (poll dorset/merino $\times$ border leicester) lambs. Animals 2020, 10, 2441. [CrossRef] [PubMed]

27. Silanikove, N. Effects of heat stress on the welfare of extensively managed domestic ruminants. Livest. Prod. Sci. 2000, 67, 1-18. [CrossRef]

28. Hales, J.R.; Brown, G.D. Net energetic and thermoregulatory efficiency during panting in the sheep. Comp. Biochem. Physiol. A Comp. Physiol. 1974, 49, 413-422. [CrossRef]

29. Franzmann, A.W.; Hebert, D.M. Variation of Rectal Temperature in Bighorn Sheep. J. Wildl. Manag. 1971, 35, 488-494. [CrossRef] 
30. Aleksiev, J. Thermoregulation in sheep. IV. Effect of heat stress on heart rate dynamics in shorn and inshorn ewes from three breeds. J. Anim. Sci. 2004, 41, 16-21.

31. Al Haidary, A.A. Physiological responses of Naimey sheep to heat stress challenge under semi-arid environments. Int. J. Agric. Biol. 2004, 2, 307-309.

32. Cheng, H.; Song, S.; Kim, G.D. Frozen/thawed meat quality associated with muscle fiber characteristics of porcine longissimus thoracis et lumborum, psoas major, semimembranosus, and semitendinosus muscles. Sci. Rep. 2021, 11, 13354. [CrossRef]

33. Tarrant, P.V. The Effects of Handling, Transport, Slaughter and Chilling on Meat Quality and Yield in Pigs-A Review. Irish J. Food Sci. Technol. 1989, 13, 79-107.

34. Greenwood, P.L.; Gardner, G.E.; Hegarty, R.S. Lamb myofibre characteristics are influenced by sire estimated breeding values and pastoral nutritional system. Aust. J. Agric. Res. 2006, 57, 627-639. [CrossRef]

35. Oishi, Y.; Taniguchi, K.; Matsumoto, H.; Ishihara, A.; Ohira, Y.; Roy, R.R. Differential responses of HSPs to heat stress in slow and fast regions of rat gastrocnemius muscle. Muscle Nerve 2003, 28, 587-594. [CrossRef] [PubMed]

36. Macías Cruz, U. Feedlot growth, carcass characteristics and meat quality of hair breed male lambs exposed to seasonal heat stress (winter vs. summer) in an arid climate. Meat Sci. 2020, 169, 108202. [CrossRef] [PubMed]

37. Archana, P.R.; Sejian, V.; Ruban, W.; Bagath, M.; Krishnan, G.; Aleena, J.; Manjunathareddy, G.B.; Beena, V.; Bhatta, R. Comparative assessment of heat stress induced changes in carcass traits, plasma leptin profile and skeletal muscle myostatin and HSP70 gene expression patterns between indigenous Osmanabadi and Salem Black goat breeds. Meat Sci. 2018, 141, 66-80. [CrossRef] [PubMed]

38. Chauhan, S.S.; Celi, P.; Leury, B.J.; Dunshea, F.R. High dietary selenium and vitamin E supplementation ameliorates the impacts of heat load on oxidative status and acid-base balance in sheep. J. Anim. Sci. 2015, 93, 3342-3354. [CrossRef] [PubMed]

39. Alcalde, M.J. Effects of farm management practices and transport duration on stress response and meat quality traits of suckling goat kids. Animal: Int. J. Anim. Biosci. 2017, 11, 1626-1635. [CrossRef] [PubMed]

40. Warriss, P.D.; Kestin, S.C.; Brown, S.N.; Knowles, T.G.; Wilkins, L.J.; Edwards, J.E.; Austin, S.D.; Nicol, C.J. The depletion of glycogen stores and indices of dehydration in transported broilers. Br. Vet. J. 1993, 149, 391-398. [CrossRef]

41. Kadim, I.T.; Mahgoub, O.; Alkindi, A.Y.; Al-Marzooqi, W.; Al-Saqri, N.M.; Almaney, M.; Mahmoud, I.Y. Effect of transportation at high ambient temperatures on physiological responses, carcass and meat quality characteristics in two age groups of Omani sheep. Asian-Aust. J. Anim. Sci. 2007, 20, 424-431. [CrossRef]

42. Kadim, I.T.; Mahgoub, O.; Khalaf, S. Effects of the transportation during hot season and electrical stimulation on meat quality characteristics of goat Longissimus dorsi muscle. Small Rumin. Res. 2014, 121, 120-124. [CrossRef]

43. Chauhan, S.S.; England, E.M. Postmortem glycolysis and glycogenolysis: Insights from species comparisons. Meat Sci. 2018, 144, 118-126. [CrossRef] 